JOSÉ DANIEL GATTI VERGNA

\title{
O NOVO SISTEMA DO TRIBUNAL ADMINISTRATIVO DA ONU
}

\author{
Dissertação de Mestrado
}

Orientador: Professor Associado Doutor Wagner Menezes

FACULDADE DE DIREITO DA UNIVERSIDADE DE SÃO PAULO

São Paulo

2015 
JOSÉ DANIEL GATTI VERGNA

\title{
O NOVO SISTEMA DO TRIBUNAL ADMINISTRATIVO DA ONU
}

\begin{abstract}
Dissertação apresentada à Banca Examinadora de Pós-Graduação em Direito, da Faculdade de Direito da Universidade de São Paulo, como exigência parcial para obtenção do título de Mestre em Direito, na área de concentração de Direito Internacional, sob a orientação do Professor Associado Doutor Wagner Menezes.
\end{abstract}

FACULDADE DE DIREITO DA UNIVERSIDADE DE SÃO PAULO São Paulo 


\section{RESUMO}

O presente trabalho propõe-se a discutir sobre os Tribunais Administrativos de Organizações Internacionais, sua dimensão jurídica no contexto da expansão do Direito Internacional contemporâneo, seus objetivos jurisdicionais, suas características específicas, seus procedimentos internos e seu conceito, a partir da análise dos fundamentos e elementos jurídicos que preenchem o conteúdo dos tribunais internacionais. Nesse sentido, o estudo remonta ao exame do vínculo existente entre as organizações internacionais, os órgãos de organizações internacionais, os funcionários internacionais que prestam serviços laborais às organizações internacionais e os Tribunais Administrativos. Por fim, será apresentado o novo sistema administrativo de solução de controvérsias da Organização das Nações Unidas, de modo a revelar o significado e as consequências que a sua reforma introduz para o futuro dos Tribunais Administrativos e para a evolução do Direito Internacional na proteção dos indivíduos.

Palavras-chave: Tribunais Internacionais. Funcionários Internacionais. Tribunais Administrativos de Organizações Internacionais. Tribunal Administrativo da Organização das Nações Unidas. 


\begin{abstract}
The following essay intends to discuss the International Administrative Tribunals of International Organizations, their legal dimension in the context of contemporary International Law expansion, its jurisdictional goals, their detailed characteristics, their internal procedures and its concept, by analyzing the reasons and legal aspects that fulfill the content of the international tribunals. To this end, the study relies on the examination of the existing connection between international organizations, the organs of international organizations, the international officials who render labor services to international organizations and the Administrative Tribunals. Finally, an approach in the new administrative dispute resolution system of the United Nations will be done, aiming to reveal the meaning and the consequences that the reform introduces to the future of the Administrative Tribunals and to the evolution of the International Law on the protection of individuals.
\end{abstract}

Keywords: International Tribunals. International Officials. International Administrative Tribunals of International Organizations. United Nations Administrative Tribunal. 


\section{INTRODUÇÃO}

Os acontecimentos que sucedem as Conferências de Haia, em 1899 e 1907, que passam pelo Tratado de Versalhes, em 1919, e que culminam no surgimento da Organização das Nações Unidas, em 1945, todo esse período deve ser compreendido como um marco temporal no desenvolvimento do Direito Internacional. Um novo olhar jurídico passou a ser dirigido para a sociedade internacional. Novos sujeitos foram concebidos, novas relações foram encetadas e novos conflitos foram deflagrados. Nesse cenário, o Direito Internacional teve alargado o seu leque normativo, sem que isso afetasse o seu alicerce principiológico e valorativo.

A finalidade do Direito reside na preservação da paz. A divergência de interesses e o abuso de poder são condições primárias para ocorrência das disputas sociais. Somente o Direito, como mecanismo regulador e harmonizador, para apaziguar os eventuais desacordos e nivelar as possíveis diferenças. A mesma função, nessa vereda, é reservada ao Direito Internacional. A aplicação das normas jurídicas internacionais encontra na paz e na proteção do indivíduo o seu propósito basilar. No último século, esse papel acabou sendo impulsionado, o que lhe viabilizou uma posição de destaque frente às questões enfrentadas pela sociedade internacional.

Não há dúvidas de que o Direito Internacional se expandiu. Como mencionado acima, novos sujeitos foram concebidos. A agenda internacional também foi ampliada, permitindo que mais temas de interesse da sociedade internacional passassem a ser tutelados pelas normas jurídicas internacionais. Ao mesmo tempo, houve a multiplicação dos meios jurídicos de solução das controvérsias internacionais, personificados na figura dos tribunais internacionais. Desse processo de jurisdicionalização do Direito Internacional, relevância é atribuída às organizações internacionais, aos funcionários internacionais e aos Tribunais Administrativos de Organizações Internacionais.

Nas últimas décadas, diversos Tribunais Administrativos foram criados por organizações internacionais, para solucionar as eventuais controvérsias existentes entre esses entes e seus funcionários. Dentro desse cenário em que adolesce o Direito Internacional na era contemporânea, a concepção dos Tribunais Administrativos de Organizações Internacionais percorre um caminho semelhante àquele que foi trilhado pelos tribunais internacionais, embora a função jurisdicional dos Tribunais Administrativos esteja apenas 
relacionada à proteção dos indivíduos que prestam serviços trabalhistas às organizações internacionais.

Equiparar os Tribunais Administrativos aos demais tribunais internacionais, porém, não decorre de uma dedutibilidade óbvia. Necessário se faz o exercício teórico dessa premissa. É certo que ambos estão conectados ao processo de jurisdicionalização do Direito Internacional, mas suas acepções jurídico-valorativas e finalidades são totalmente distintas. Em geral, os tribunais internacionais possuem sua origem nos tratados e possuem poderes jurisdicionais para dirimir conflitos entre Estados. Os Tribunais Administrativos, por sua vez, estão vinculados ao aparato orgânico das organizações internacionais e são constituídos para resolver as disputas entre as próprias organizações internacionais e seus funcionários.

Essa proteção jurídica se faz imperativa porque tanto a organização internacional como os funcionários internacionais não estão vinculados à jurisdição dos Estados. Ambos possuem atuação exclusiva na esfera da jurisdição internacional. Em verdade, os atos perpetrados pelas organizações internacionais voltam-se para o interesse da sociedade internacional. Esses atos, por sua vez, são preenchidos, na sua essência, pelo trabalho que é realizado pelos funcionários internacionais. Entre os dois, existe uma relação de mutualismo, pois um depende do outro para que seja possível a consecução das atividades trabalhistas e institucionais.

Nem todos que prestam serviços às organizações internacionais, entretanto, são considerados funcionários internacionais. Há indivíduos que, apesar de trabalharem para esses organismos, não gozam das imunidades e de determinados privilégios que foram conferidos pelo Direito Internacional e que são imprescindíveis à execução das funções laborais no âmbito internacional. Por outro lado, é correto afirmar que nem todos devem ou podem possuir essas prerrogativas. Mas quem são aqueles que carregam o semblante de funcionários internacionais? A presente dissertação, todavia, não pretende solucionar este dilema, que ainda carece de um estudo mais aprofundado pela doutrina jurídica.

Mesmo assim, em paralelo ao questionamento anterior, estão os Tribunais Administrativos de Organizações Internacionais. Quem são? O que são? Como efetivamente contextualizar os Tribunais Administrativos na seara do Direito Internacional contemporâneo? Como os Tribunais Administrativos se prestam para a solução das disputas havidas entre a organização internacional e seus funcionários? Como funcionam os seus procedimentos internos? Quais são os seus objetivos? Quais são os problemas ou críticas desses órgãos jurisdicionais? Como se projeta o desenvolvimento da figura dos Tribunais Administrativos para o futuro próximo? 
Com foco na última pergunta, será apresentado o sistema administrativo de solução de controvérsias da Organização das Nações Unidas. Dos antigos procedimentos administrativos e do extinto Tribunal Administrativo da Organização das Nações Unidas para os novos procedimentos extrajudiciais e para o atual modelo judicial de resolução de litígios trabalhistas, o que mudou? De que forma os mecanismos de acesso promovidos pelo novo sistema são mais benéficos e viáveis à proteção jurídica dos trabalhadores de organizações internacionais? Como entender esta mudança no plano da aplicação das normas jurídicas internacionais?

Partindo de uma perspectiva idealista do Direito Internacional, essas indagações pretendem ser respondidas pelo pretende trabalho, cuja base de pesquisa está alinhada aos métodos histórico e dedutivo. Antes de tudo, salienta-se o seguinte recorte metodológico: serão estudados apenas os Tribunais Administrativos que estão inseridos no Sistema da Organização das Nações Unidas, com especial atenção para o sistema administrativo de solução de controvérsias da Organização das Nações Unidas. Nesse sentido, enfoque foi dado às fontes primárias e à bibliografia existente sobre o tema, ainda que de difícil acesso no plano interno e internacional.

Quanto às fontes primárias, referência é feita aos documentos de organizações internacionais, como tratados constitutivos, resoluções, ordens e notificações administrativas. Especificamente em relação aos Tribunais Administrativos examinados, importância é dada à apreciação dos estatutos e das regras de procedimento desses órgãos judiciais, da jurisprudência internacional e daquilo que for aplicável à compreensão desses entes no âmbito do Direito Internacional. A respeito da bibliografia, servirão principalmente de aporte teórico os estudos e trabalhos doutrinários mais recentes que foram feitos em relação ao tema pesquisado.

A partir disso, no primeiro capítulo será realizado um estudo introspectivo das organizações internacionais, dando especial importância aos órgãos que dão sustentáculo à sua estrutura administrativa. Em seguida, será feita uma abordagem bastante ampla dos funcionários internacionais, revelando a sua origem histórica, as suas características principais e sua relação com os privilégios e imunidades outorgados pelo Direito Internacional, e com as organizações internacionais. No final, seguindo o corte propositivo, será apresentado o Sistema da Organização das Nações Unidas e serão elencados os Tribunais Administrativos que nele estão inseridos.

No segundo capítulo, o trabalho pretende contextualizar a figura dos Tribunais Administrativos no cenário da jurisdicionalização do Direito Internacional. Para isso, será 
feito o exame do surgimento dos tribunais internacionais, das suas características e do seu conceito jurídico. Depois, será avaliada a dimensão jurídica dos Tribunais Administrativos de Organizações Internacionais, a partir da análise da sua origem e das suas finalidades, da natureza jurídica das controvérsias julgadas e, também, do seu conceito jurídico. Nesse ponto, anseia-se elucidar o significado desses órgãos jurisdicionais para o Direito Internacional contemporâneo.

Finalmente, no terceiro capítulo será feita a abordagem do antigo sistema administrativo de solução de controvérsias da Organização das Nações Unidas, centralizando a pesquisa no seu Tribunal Administrativo. Adiante, esforços serão direcionados na compreensão do recente processo de reforma desse sistema, que acabou resultando na criação de um novo modelo administrativo de solução de disputas. Compreender os motivos dessa mudança e as suas consequências para os demais Tribunais Administrativos de Organizações Internacionais e para o próprio Direito Internacional faz parte dos objetivos finais perseguidos por esta dissertação. 


\section{CONCLUSÃO}

Definitivamente, o surgimento e multiplicação dos tribunais internacionais ocorridos no último século representam um ponto de inflexão no desenvolvimento e expansão do Direito Internacional. Ao delegar às normas jurídicas internacionais a autoridade necessária para resolver os conflitos de natureza internacional, a sociedade internacional conferiu ao Direito Internacional um novo patamar de legitimação, que lhe acabou impondo primazia frente aos demais meios de solução de controvérsias. É nesse contexto que estão situados os Tribunais Administrativos de Organizações Internacionais.

Os Tribunais Administrativos foram criados para solucionar as disputas entre as organizações internacionais e seus funcionários. Ambos, organizações e trabalhadores, são tutelados por normas de Direito Internacional. Não estão, desse modo, atrelados à jurisdição estatal, e sim à jurisdição internacional. Isso ocorre porque as organizações possuem personalidade jurídica internacional. Os funcionários, na mesma medida, também gozam de imunidades e privilégios que foram outorgados pelo Direito Internacional. Os dois, portanto, estão necessariamente vinculados aos interesses da sociedade internacional.

Nessa conjuntura, no primeiro capítulo, o presente trabalho redigiu sobre as organizações internacionais, os órgãos que preenchem a sua estrutura administrativa e a relação destes com os Tribunais Administrativos. Em seguida, foram apresentadas as características que dão forma e conteúdo aos funcionários internacionais, e as dificuldades de promover a sua proteção jurídica uma vez que seus atos, assim como os protagonizados pelas organizações internacionais, não estão ligados à jurisdição dos Estados onde são realizadas as atividades laborais e institucionais.

No segundo capítulo, a dissertação se debruçou sobre o processo de jurisdicionalização do Direito Internacional, com enfoque na multiplicação dos tribunais internacionais. Temas importantes como acesso à justiça no plano internacional e controvérsias internacionais foram discutidos, para que fosse possível compreender o conceito atribuído aos tribunais internacionais e sua relação com os Tribunais Administrativos, dentro da linha metodológica traçada no capítulo anterior. A partir disso, numa perspectiva exclusiva do Direito Internacional, tornou-se viável compreender a dimensão jurídica dos Tribunais Administrativos. 
No último capítulo, apresentou-se o sistema administrativo de solução de controvérsias da Organização das Nações Unidas. Foram analisados, nesse sentido, os mecanismos que eram utilizados pelo modelo antigo e, a partir da sua reforma, os novos instrumentos que foram criados e que passaram a oferecer maior proteção jurídica aos funcionários e demais trabalhadores da Organização das Nações Unidas. Em especial, destaque foi dado aos procedimentos judiciais, que antes eram realizados exclusivamente pelo Tribunal Administrativo da Organização das Nações Unidas, e que agora passaram a ser divididos, em um duplo grau de jurisdição, entre o Tribunal de Disputas das Nações Unidas e o Tribunal de Apelação das Nações Unidas.

A partir da leitura do trabalho, denota-se que os Tribunais Administrativos foram criados para prover ao funcionário internacional o acesso à justiça. São órgãos judiciais, de natureza internacional, criados por organizações internacionais, de quem receberam poderes jurisdicionais para julgar, de forma independente, as controvérsias entre a organização e os seus funcionários. São, assim, considerados também tribunais internacionais. $\mathrm{O}$ acesso à justiça é assegurado por meio de procedimentos administrativos e judiciais. Naqueles, prevalece o processo de mediação, enquanto nestes está propriamente a tutela jurídica promovida pelos Tribunais Administrativos.

Essa proteção, por sua vez, deve ser efetiva. A simples existência do acesso à justiça não é suficiente para determinar que o funcionário de organização internacional teve a tutela adequada para a proteção dos seus direitos. Esse acesso deve possuir qualidade. Princípios e regras jurídicas basilares, que também possuem respaldo no Direito Internacional, devem ser respeitados ou, do contrário, o indivíduo estará sendo privado da justiça que lhe é de direito. Nesse ponto, para que os Tribunais Administrativos cumpram com a sua finalidade jurisdicional, é preciso que as suas decisões envolvam determinadas garantias de direito.

No caso do sistema administrativo de solução de controvérsias da Organização das Nações Unidas, a reforma conseguiu concretizar que esses princípios e garantias passassem a orbitar, de forma qualitativa, a esfera jurídica do trabalhador. Os órgãos e procedimentos internos do novo sistema gozam agora de maior independência. Os processos administrativos e judiciais inibiram as eventuais diferenças existentes entre as partes litigantes. $\mathrm{O}$ acesso, igualmente, tornou-se mais profissionalizado, seja pela capacidade técnica da assistência e representação legal dos indivíduos, seja pelo modo discricionário de seleção de juízes e assistentes judiciais.

Nos últimos anos, como visto, alguns julgados têm sido produzidos por tribunais nacionais, desqualificando o acesso promovido por Tribunais Administrativos de 
Organizações Internacionais, fundamentando as suas decisões em tratados de Direitos Humanos. Ao notarem que os procedimentos administrativos e judiciais das organizações internacionais não levam em consideração os direitos e deveres elementares do devido processo legal, é concedido o acesso desses trabalhadores à jurisdição estatal. Consequentemente, as imunidades dos funcionários e das organizações internacionais são afastadas, de modo que o litígio é processado nos termos das leis internas.

Nesse contexto, a reforma promovida no sistema administrativo de solução de controvérsias da Organização das Nações Unidas representa uma luz a ser seguida pelos demais sistemas administrativos de resolução de disputas de outras organizações internacionais. Não apenas porque instaurou o duplo grau de jurisdição, mas também porque facilitou esse acesso aos trabalhadores, proporcionando-lhes mais informação e instrumentos para defenderem os seus direitos. Em relação ao futuro, espera-se o aperfeiçoamento da proteção aos indivíduos, porque neles é que resta o alicerce e legitimidade da aplicação das normas de Direito Internacional. 


\section{REFERÊNCIAS}

\section{REFERÊNCIAS LITERÁRIAS}

ABI-SAAB, G. Fragmentation or unification: some concluding remarks, 31 N.Y.U. J. INT'L L. \& POL. 919 (1999).

ACCIOLY, H. Tratado de direito internacional público. $3^{a}$ ed. São Paulo: FUNAG, Quartier Latin, 2009, vol. 2.

ACCIOLY, H.; SILVA, G. E. N.; e CASELLA, P. B. Manual de direito internacional público. São Paulo: Saraiva, 2009.

ALVARENGA, R. Z. A organização internacional do trabalho e a proteção aos direitos humanos do trabalhador. São Paulo: LTr, vol. 71, n. 5, mai., 2007.

AMARAL JÚNIOR, A. Introdução ao direito internacional público. São Paulo: Atlas, 2008.

AMERASINGHE, C. F. Discretion in disciplinary cases. In: ZIADÉ, N. G. (ed.). Problems of international administrative law: on the occasion of the twentieth anniversary of the World Bank Administrative Tribunal. Leiden, Boston: Martinus Nijhoff Publishers, 2008.

Principles of institutional law of international organizations. $2^{\mathrm{a}}$ ed.

Cambridge: Cambridge Press, 2005.

Problems relating to promotion in the law of the international civil service, Max Planck Institute (für ausländisches öffentliches Recht und Völkerrecht), 1991.

- Reflections on internal judicial systems of international organizations. In: ELIAS, O. O. (ed.). The development and effectiveness of 
international administrative law: on the occasion of the thirtieth anniversary of the World Bank Administrative Tribunal. Queen Mary Studies in International Law, v. 8. Leiden, Boston: Martinus Nijhoff Publishers, 2012.

The law of international civil service: as applied by international administrative tribunals. $2^{\text {a }}$ ed. Oxford: Clarendon Press, 1994.

ARISTÓTELES. Política. Tradução, introdução e notas: Mário da Gama Kury. Instituto Nacional do Livro: Brasília: Editora Universidade de Brasília, 1985.

BAPTISTA, L. O. Imunidade de jurisdição na execução dos projetos de cooperação entre o PNUD e o governo brasileiro. In: BASSO, M.; e CARVALHO, P. L. (coord.). Lições de direito internacional: estudos e pareceres de Luiz Olavo Baptista. Curitiba: Juruá, 2008.

BASSO, M.; e CARVALHO, P. L. (coord.). Lições de direito internacional: estudos e pareceres de Luiz Olavo Baptista. Curitiba: Juruá, 2008.

BASTID, S. Les traités dans la vie internationale: conclusion et effets. Paris: Economica, 1985.

Les tribunaux administratifs internationaux et leur jurisprudence.

Collected Courses of The Hague Academy of International Law. Haia: Martinus Nijhoff Publishers, 1957.

BOBBIO, N. A era dos direitos. Rio de Janeiro: Campus, 1992.

BOULOS, C. Decisão do STF: organismos internacionais e imunidade à jurisdição trabalhista, UOL, Última Instância, 18 de maio de 2013.

BRANT, L. N. C. Fundamentos da existência e validade do direito internacional. Revista da Faculdade de Direito da Universidade Federal de Minas Gerais, Belo Horizonte, n. 62, jan./jun., 2013. 
BROWLIE, I. Princípios de direito internacional. Tradução: Maria Manuela Farrajota, Maria João Santos, Victor Richard Stockinger, Patrícia Galvão Teles. Lisboa: Fundação Calouste Gulbenkian, 1997.

BROWN, C. The cross-fertilization of principles relating to procedure and remedies in the jurisprudence of international courts and tribunals, 30 Loy. L.A. Int'l \& Comp. L. Rev. 219 (2008).

CANÇADO TRINDADE, A. A. A proteção internacional dos direitos humanos: fundamentos jurídicos e instrumentos básicos. São Paulo, Saraiva, 1991.

Direito das organizações internacionais. Belo Horizonte: Del Rey, 2002.

Os tribunais internacionais contemporâneos. Brasília: FUNAG, 2013.

CAPPELLETTI, M.; e GARTH, B. Access to justice: the worldwide movement to make rights effective, a general report. Tradução: Ellen Gracie Northfleet. Porto Alegre: Sérgio Antônio Fabris Editor, 1988.

CARVALHO RAMOS, A. Teoria geral de direitos humanos na ordem internacional. Rio de Janeiro, São Paulo, Recife: Renovar, 2005.

CASElla, P. B. Fundamentos do direito internacional pós-moderno. São Paulo: Quartier Latin, 2008.

Reforma da ONU, pós-Kelsen. In: Seminário sobre a reforma da ONU, 21 de agosto de 2009. IV Conferência Nacional de Política Externa e Política Internacional (CNPEPI): o Brasil no mundo que vem aí. Brasília: FUNAG, 2010.

CASElla, P. B.; CELli JUNIOR, U.; MEIRELlES, E.; e POLIDO, F. B. P. (coord.). Direito internacional, humanismo e globalidade. $1^{a}$ ed. São Paulo: Atlas, 2008. 
CASELLA, P. B.; e CARVALHO RAMOS, A. (coord.). Direito internacional: homenagem a Adherbal Meira Mattos. São Paulo: Quartier Latin, 2009.

CHARNEY, J. I. The impact on the international legal system of the growth of international courts and tribunals, 31 N.Y.U. J. INT'L L. \& POL. 697 (1999).

CHIOVENDA, G. Instituições de direito processual civil. $3^{\text {a }}$ ed. São Paulo: Saraiva, 1969.

CINTRA, A. C. A.; GRINOVER, A. P.; e DINAMARCO, C. R. Teoria geral do processo. $24^{\mathrm{a}}$ ed. São Paulo: Malheiros, 2008.

COMOGLIO, L. P. Accesso alle corti e garanzie constituzionali. In: YARSHELL, F. L.; e MORAES, M. Z. (coord.). Estudos em homenagem à professora Ada Pellegrini Grinover. $1^{\mathrm{a}}$ ed. São Paulo: Editora DPJ, 2005.

COMPARATO, F. K. A afirmação histórica dos direitos humanos. $3^{\mathrm{a}}$ ed. São Paulo: Saraiva, 2003.

COMTET-SIMPSON, C. The ILO administrative tribunal, Geneva, 2009.

CRETELLA JUNIOR, J.; e CRETELLA NETO, J. Criação dos tribunais administrativos internacionais e a relevância de sua atividade. In: CASELLA, P. B.; CELLI JUNIOR, U.; MEIRELLES, E.; e POLIDO, F. B. P. (coord.). Direito internacional, humanismo e globalidade. $1^{\mathrm{a}}$ ed. São Paulo: Atlas, 2008.

. Tribunais administrativos internacionais. Revista de Direito Administrativo, n. 239. Rio de Janeiro: jan./mar., 2005.

DALLARI, D. A. Teoria geral do estado. $2^{a}$ ed. São Paulo: Saraiva, 1998.

DALLARI, P. B. A. Administrative tribunals of international organizations and world constitutionalism. In: ELIAS, O. O. (ed.). The development and effectiveness of international administrative law: on the occasion of the thirtieth anniversary of the World 
Bank Administrative Tribunal. Queen Mary Studies in International Law, v. 8. Leiden, Boston: Martinus Nijhoff Publishers, 2012.

Atualidade dos tribunais administrativos de organizações internacionais. Tese de livre-docência apresentada à apresentada à Faculdade de Direito do Largo de S. Francisco, USP. São Paulo, 2009.

DHINAKARAN, R. Law of international civil service: a venture into legal theory. International Organizations Law Review, n. 8. Leiden, Boston: Martinus Nijhoff Publishers, 2011.

DINAMARCO, C. R. Instituições de direito processual civil. $5^{\text {a }}$ ed. São Paulo: Malheiros, 2009.

DINH, N. Q.; DAILLER, P.; PELLET, A. Direito internacional público. Tradução: Vitor Marques Coelho. $2^{\mathrm{a}}$ ed. Lisboa: Fundação Calouste Gulbenkian, 2003.

DONNELLY, J. International human rights. $2^{\text {a }}$ ed. Oxford: Westview Press, 1998.

DUPUY, P. M. The danger of fragmentation or unification of the international legal system and the International Court of Justice, 31 N.Y.U. J. INT'L L. \& POL. 791 (1999).

ELIAS, O. O. (ed.). The development and effectiveness of international administrative law: on the occasion of the thirtieth anniversary of the World Bank Administrative Tribunal. Queen Mary Studies in International Law, v. 8. Leiden, Boston: Martinus Nijhoff Publishers, 2012.

FERRAZ JÚNIOR, T. S. Introdução ao estudo do direito: técnica, decisão, dominação. $5^{\text {a }}$ ed. São Paulo: Atlas, 2007.

FREDERICO MARQUES, J. Instituições de direito processual civil. $2^{\mathrm{a}}$ ed. Rio de Janeiro: Forense, 1962. 
GENTOT, M. Le contrôle du pouvoir discrétionnaire par les tribunaux administratifs internationaux. In: ZIADÉ, N. G. (ed.). Problems of international administrative law: on the occasion of the twentieth anniversary of the World Bank Administrative Tribunal. Leiden, Boston: Martinus Nijhoff Publishers, 2008.

GORMAN, R. A. The development of international employment law: my experience on international administrative tribunals as the World Bank and the Asian Development Bank. In: ZIADÉ, N. G. Problems of international administrative law: on the occasion of the twentieth anniversary of the World Bank administrative tribunal. Leiden, Boston: Martinus Nijhoff Publishers, 2008.

GOSPEAL, H. Quality of working life: a review on changes in work organization, conditions of employment and work-life arrangements, Conditions of Work and Employment Series, n. 1. International Labour Organization, 2003.

GUALAZZI, E. L. B. Direito internacional administrativo. São Paulo: Edições Inteligentes, 2005.

GULATI, R. The internal dispute resolution regime of the United Nations: has the creation of the United Nations Dispute Tribunal and United Nations Appeals Tribunal remedied the flaws of the United Nations Administrative Tribunal? Max Planck Yearbook of United Nations Law, v. 15, 2011.

HABERMAS, J. Direito e democracia: entre facticidade e validade. Tradução: Flávio Beno Siebeneichler. Rio de Janeiro: Tempo Brasileiro, vol. 1, 1997.

HAMMARSKJÖLD, D. The international civil servant in law and in fact. Lecture delivered to Congregation at Oxford University. Oxford: Clarendon Press, 1961.

HOBBES, T. Leviatã: ou matéria, forma e poder de uma república eclesiástica e civil. Tradução: João Paulo Monteiro e Maria Beatriz Nizza da Silva. Revisão da tradução: Eunice Ostrensky. $1^{a}$ ed. São Paulo: Martins Fontes, 2003. 
HURTER, E. Access to justice: to dream the impossible dream, 44 Comp. \& Int'l L.J. S. Afr. 408 (2011).

JACKSON, J. H. Fragmentation or unification among international institutions: the World Trade Organization, 31 N.Y.U. J. INT'L L. \& POL. 823 (1999).

KANT, I. Ideia de uma história universal de um ponto de vista cosmopolita. São Paulo: Martins Fontes, 2011.

KELSEN, H. Princípios do direito internacional. Ijuí: Editora Unijui, 2010. Teoria pura do direito. São Paulo: Martins Fontes, 2006.

KINGSBURY, B. Foreword: is the proliferation of international courts and tribunal a systemic problem? 31 N.Y.U. J. INT'L L. \& POL. 679 (1999).

KOSKENNIEMI, M. L'utilisation du "raisonnable" par le juge international: discours juridique, raison et contradictions, 1997, Book Review of O. Corten, 94 AJIL 198, 2000.

The gentle civilizer of nations: the rise and fall of international law 1870-1960. Cambridge: Cambridge University Press, Hersch Lauterpacht Memorial Lectures, 2001.

LAFER, C. A internacionalização dos direitos humanos. São Paulo: Manole, 2011.

LASMAR. A. L. Francisco de vitória: um espanhol na ONU? In: MENEZES, W. (coord.). Direito internacional clássico e seu fundamento. Belo Horizonte: Arraes, 2014.

LUHMANN, N. Legitimação pelo procedimento. Tradução: Maria da Conceição CorteReal. Coleção Pensamento Jurídico. Brasília: Editora Universidade de Brasília, 1969.

MACHADO JUNIOR, C. P. S. Aspectos do direito do trabalho no direito comparado. São Paulo: LTr, 2001. 
MADRUGA FILHO, A. P.; e GÁRCIA, M (coord.). A imunidade de jurisdição e o judiciário brasileiro. Brasília: CEDI, 2002.

MATTOS, A. M. Direito das organizações internacionais e direito da integração. Rio de Janeiro, São Paulo, Recife: Renovar, 2008.

MELLO, C. A. Curso de direito internacional público. 10ª ed. Rio de Janeiro: Renovar, 1994, vol. 1.

MENEZES, W. Tribunais internacionais: jurisdição e competência. São Paulo: Saraiva, 2013 .

. (coord.). Direito internacional clássico e seu fundamento. Belo Horizonte: Arraes, 2014.

. (coord.). Direito do mar: desafios e perspectivas. Belo Horizonte: Arraes, 2014.

(coord.). Direito internacional em expansão. Anais do $10^{\circ}$ Congresso Brasileiro de Direito Internacional, v. 1. Belo Horizonte: Arraes, 2012.

Ordem global e transnormatividade. São Paulo: Unijui, 2005.

Os princípios no direito internacional. In: CASELLA, P. B.; e CARVALHO RAMOS, A. (coord.). Direito internacional: homenagem a Adherbal Meira Mattos. São Paulo: Quartier Latin, 2009.

. Reforma da Organização das Nações Unidas: perspectivas e proposições a partir do direito internacional, Seminário sobre a reforma da ONU, 21 de agosto de 2009. IV Conferência Nacional de Política Externa e Política Internacional (CNPEPI): o Brasil no mundo que vem aí. Brasília: FUNAG, 2010.

MERCADANTE, A. A.; CELli JUNIOR, U.; e ARAÚJO, L. R. (coord.). Blocos econômicos e integração na América Latina, África e Ásia. Curitiba: Juruá Editora, 2007. 
MEZYAEV, A. UN and issue of Ukraine: General Assembly v. UN Security Council, Strategic Culture Foundation, Online Journal, 20 de março de 2014.

MOLL, L. O. Imunidades internacionais: tribunais nacionais ante a realidade das organizações internacionais. $2^{\mathrm{a}}$ ed. Brasília: FUNAG, 2011.

MONTGOMERY, N. As organizações internacionais como sujeito de direito internacional. In: MERCADANTE, A. A.; CELLI JUNIOR, U.; e ARAÚJO, L. R. (coord.). Blocos econômicos e integração na América Latina, África e Ásia. Curitiba: Juruá Editora, 2007.

NOGUEIRA, A. Jurisdição das liberdades públicas. Rio de Janeiro: Renovar, 2005.

PANGALANGAN, R. C. Constraints on judicial review of managerial discretion: substantive and procedural. In: ZIADÉ, N. G. (ed.). Problems of international administrative law: on the occasion of the twentieth anniversary of the World Bank Administrative Tribunal. Leiden, Boston: Martinus Nijhoff Publishers, 2008.

PAPANIKOLAOU, K. (ed.). International administrative tribunals in a changing world, United Nations Administrative Tribunal Conference, New York, 2007.

PHILIP, M. C.; e DE CARA, M. Nature et évolution de la juridiction internationale, La juridiction internationale permanente, Colloque de Lyon, Société Française pour le Droit Internationale. Paris: Pedone, 1987.

PINTO, M. Fragmentation or unification among international institutions: human rights tribunals, 31 N.Y.U. J. INT'L L. \& POL. 833 (1999).

PIOVESAN, F. Direitos humanos e o direito constitucional internacional. $1^{\mathrm{a}}$ ed. São Paulo: Max Limonad, 1996. 
REINISCH, A. Administrative tribunals and questions of jurisdiction and immunity. In: PAPANIKOLAOU, K. (ed.). International administrative tribunals in a changing world, United Nations Administrative Tribunal Conference, New York, 2007.

The immunity of international organizations and the jurisdiction of their administrative tribunals. Chinese Journal of International Law, vol. 7, n. 2, Oxford University Press, 2008.

REUTER, P. Le développement de l'ordre juridique internationale: écrits de droit international. Paris: Economica, 1995.

ROMANO, C. P. R. A taxonomy of international rule of law institutions, Journal of International Dispute Settlement, vol. 2, n. 1 (2011).

International justice and developing countries: a qualitative analysis, The law and practice of international courts and tribunals, Netherlands: Kluwer Law International, 2002.

The proliferation of international judicial bodies: the pieces of the puzzle, 31 N.Y.U. J. INT'L L. \& POL. 709 (1999).

RUZIÉ, D. Droit international public. Paris: Dalloz, 1996.

SALMON, J. Dictionnaire de droit international public. Bruxelas: Bruylant, 2001.

SEITENFUS, R. Manual das organizações internacionais. Porto Alegre: Livraria do Advogado, 1997.

SHANY, Y. Assessing the effectiveness of international courts: a goal-based approach, The American Journal of International Law, vol. 106, n. 2, 2012.

SHAW, M. N. International law. 5 ${ }^{\text {a }}$ ed. New York: Cambridge University Press, 2003. 
SILVA SOARES, G. F. da. Origens e justificativas da imunidade de jurisdição. In: MADRUGA FILHO, A. P.; e GÁRCIA, M (coord.). A imunidade de jurisdição e o judiciário brasileiro. Brasília: CEDI, 2002.

STEINWASCHER NETO, H. Principais influências do ius gentium romano na obra "O direito da guerra e da paz" de Hugo Grócio. In: MENEZES, W. (coord.). Direito internacional clássico e seu fundamento. Belo Horizonte: Arraes, 2014.

SÜSSEKIND, A. Direito internacional do trabalho. São Paulo: LTr, 2000.

SZASZ, P.; e INGADOTTIR, T. The UN and the ICC: the immunity of the UN and its officials, Leiden Journal of International Law, vol. 14, 2001.

TREVES, T. Conflicts between the International Tribunal for the Law of the Sea and the International Court of Justice, 31 N.Y.U. J. INT'L L. \& POL. 809 (1999).

VALTICOS, N. A propos du contrôle du pouvoir discrétionnaire par les tribunaux administratifs des organisations internationales. In: ZIADÉ, N. G. (ed.). Problems of international administrative law: on the occasion of the twentieth anniversary of the World Bank Administrative Tribunal. Leiden, Boston: Martinus Nijhoff Publishers, 2008.

VERGNA, J. D. G. A discussão da competência dos tribunais administrativos internacionais no âmbito da Corte Internacional de Justiça. In: MENEZES, W. (coord.) Direito internacional em expansão. Anais do $10^{\circ}$ Congresso Brasileiro de Direito Internacional, v. 1. Belo Horizonte: Arraes, 2012.

Fundamentos do direito internacional: considerações preliminares sobre a perspectiva kelseniana. In: MENEZES, W (coord.). Direito internacional clássico e seu fundamento. Belo Horizonte: Arraes, 2014.

Solução de controvérsias trabalhistas dos funcionários do Tribunal Internacional para o Direito do Mar (ITLOS). In: MENEZES, W. (coord.). Direito do mar: desafios e perspectivas. Belo Horizonte: Arraes, 2014. 
VICUÑA, F. O. Le contrôle du pouvoir discrétionnaire de l'administration par les tribunaux administratifs internationaux: observations à la lumière de la pratique du Tribunal Administratif de la Banque Mondiale. In: ZIADÉ, N. G. (ed.). Problems of international administrative law: on the occasion of the twentieth anniversary of the World Bank Administrative Tribunal. Leiden, Boston: Martinus Nijhoff Publishers, 2008.

VILLAMIL. M. P. Historia de la diplomacia y las relaciones internacionales. Asunción: Litocolor SRL, 2010.

YAMAGUCHI, T. Comparabilité des droits dans les cultures juridiques différentes: à propos de la pluralité d'origines d'inspiration dans les règles juridiques du droit du travail. Paris: Revue Internationale de Droit Comparé, 1999.

YARSHELL, F. L.; e MORAES, M. Z. (coord.). Estudos em homenagem à professora Ada Pellegrini Grinover (coord.). 1 ${ }^{\text {a }}$ ed. São Paulo: Editora DPJ, 2005.

ZIADÉ, N. G. (ed.). Problems of international administrative law: on the occasion of the twentieth anniversary of the World Bank Administrative Tribunal. Leiden, Boston: Martinus Nijhoff Publishers, 2008.

Some practical issues arising in international administrative tribunals. In: ZIADÉ, N. G. (ed.). Problems of international administrative law: on the occasion of the twentieth anniversary of the World Bank Administrative Tribunal. Leiden, Boston: Martinus Nijhoff Publishers, 2008.

\section{REFERÊNCIAS JURISPRUDENCIAIS}

\subsection{Jurisprudência Internacional}

2.1.1. Corte Europeia de Direitos Humanos

Consultivo, Application n. 26083/94 (Waite and Kennedy vs. Germany), 1999.

2.1.2. Corte Internacional de Justiça 
Consultivo, Application for Review of Judgment n. 158 of the UN Administrative Tribunal, 1973.

Consultivo, Application for Review of Judgment n. 273 of the UN Administrative Tribunal, 1982.

Consultivo, Application for Review of Judgment n. 333 of the UN Administrative Tribunal, 1987.

Consultivo, Efeitos dos julgamentos do Tribunal Administrativo das Nações Unidas, 1954.

Consultivo, Julgamento n. 2867 do Tribunal Administrativo da Organização Internacional do Trabalho sobre uma reclamação proposta contra o Fundo Internacional para o Desenvolvimento da Agricultura, 2012.

Consultivo, Julgamentos do Tribunal Administrativo da OIT sobre as reclamações feitas contra a UNESCO, 1956.

Consultivo, Ressarcimento dos danos sofridos a serviço da ONU, 1949.

Contencioso, Ambatielos, 1953.

2.1.3. Corte Permanente de Justiça Internacional

Contencioso, Mavrommatis, 1924.

2.1.4. Tribunal Administrativo do Banco Mundial

Judgment n. 452/2011 (B.O. v. IBRD), 2011.

2.1.5. Tribunal Administrativo do Fundo Monetário Internacional

Judgment n. 2013-2 (B. Tosko Bello v. IMF), 2013.

2.1.6. Tribunal Administrativo da Organização Internacional do Trabalho

Judgment n. 2120/2002 (I.M.B. v. IAEA), 2002.

Judgment n. 2639/2007 (S.R.M. v. WTO), 2007.

Judgment n. 2662/2007 (A.G.S. v. UNIDO), 2007. 
Judgment n. 2722/2008 (many v. Eurocontrol), 2008.

Judgment n. 2760/2008 (J.L.H. v. IAEA), 2008.

Judgment n. 2833/2009 (T.D.V.C. v. ILO), 2009.

Judgment n. 2860/2009 (E.H. v. FAO), 2009.

Judgment n. 2913/2010 (S.M.S. v. WHO), 2010.

Judgment n. 2944/2010 (C.C. v. UNESCO), 2010.

Judgment n. 3020/2011 (F.M. v. WTO), 2011.

Judgment n. 3073/2012 (E.A.M.P. v. ILO), 2012.

Judgment n. 3099/2012 (M.A. v. ESO), 2012.

Judgment n. 3105/2012 (Dutch nationals v. EPO), 2012.

Judgment n. 3141/2012 (I.T. v. WHO), 2012.

Judgment n. 3256/2014 (M.S. v. EPO), 2014.

Judgment n. 3264/2014 (M.J. v. ILO), 2014.

Judgment n. 3295/2014 (R.D.A.G. v. PAHO), 2014.

Judgment n. 3337/2014 (P.D.M. v. EPO), 2014.

2.1.7. Tribunal Administrativo da Organização das Nações Unidas

Judgment n. 1157/2004 (Andronov v. UN), 2004.

Judgment n. UNDT/2013/002 (Makwaka v. Secretary General of the United Nations), 2013. Judgment n. UNDT/2013/038 (Santos v. Secretary General of the United Nations), 2013. Judgment n. UNDT/2013/056 (Lex v. Secretary General of the United Nations), 2013. Judgment n. UNDT/2013/094 (Bali v. Secretary General of the United Nations), 2013.

Judgment n. 2014-UNAT-401 (ref. Judgment n. UNDT/2013/005, Zeid v. Secretary General of the United Nations), 2014.

Judgment n. 2014-UNAT-405 (ref. Judgment n. UNDT/2013/008, Obino v. Secretary General of the United Nations), 2014.

Judgment n. 2014-UNAT-426 (ref. Judgment n. UNDT/2013/025, Kacan v. Secretary General of the United Nations), 2014.

\subsection{Jurisprudência Nacional}


2.2.1. Supremo Tribunal Federal

Apelação Cível n. 9696, Relator: Francisco Rezek.

RE n. 583.050, Relator: Ministro Cezar Peluso.

RE n. 586.453, Relatora: Ministra Ellen Gracie.

2.2.2. Tribunal Regional do Trabalho

RO n. 00014-2011-016-10-00-5, $10^{a}$ Região, $3^{a}$ Turma, 16 ${ }^{a}$ Vara do Trabalho de Brasília/DF, Relator: Desembargador Ribamar Lima Junior, Julgamento em 27/11/2013.

2.2.3. Tribunal Superior do Trabalho

AI-RR n. 242/2005-000-10-00-1, Relator: Ministro Ives Gandra Martins, Julgamento em $02 / 09 / 2008$.

\section{DOCUMENTOS INTERNACIONAIS}

\subsection{Acordos Internacionais}

Australian Foreign States Immunities Act (1985).

Australian Foreign States Immunities Act (1985).

Canada Act to Provide for State Immunity in Canadian Courts (1982).

Carta das Nações Unidas (1945).

Convenção Africana dos Direitos do Homem e dos Povos (1981).

Convenção Americana de Direitos Humanos (Pacto de São José da Costa Rica) (1969).

Convenção de Privilégios e Imunidades das Nações Unidas (1946).

Convenção de Viena sobre Direito dos Tratados entre Estados (1969).

Convenção de Viena sobre o Direito dos Tratados entre Estados e Organizações Internacionais (1986).

Convenção de Viena sobre Relações Diplomáticas (1961).

Convenção dos Privilégios e Imunidades das Nações Unidas (Convenção de Londres) (1946).

Convenção Europeia de Direitos Humanos (1950). 
Convenção Europeia de Direitos Humanos (Protocolo n. 11) (1998).

Convenção sobre Privilégios e Imunidades das Agências Especializadas das Nações Unidas

(Convenção de Nova Iorque) (1947).

Declaração de Filadélfia (1944).

Declaração de Montreal (1946).

Declaração Universal dos Direitos Humanos (1948).

Estatuto de Roma (1998).

Foreign Sovereign Immunities Act (1976).

International Organization Immunities Act (1947).

Pacto Internacional sobre Direito Civis e Políticos (1966).

Singapour State Immunity Act (1981).

South Africa Foreign States Immunity Act (1981).

Tratado de Versalhes (1919).

United Kingdom State Immunity Act (1978).

United Nations Participation Act (1945).

\subsection{Documentos de Organizações Internacionais}

3.2.1. Fundo Monetário Internacional

Resolução n. 48/1 (1992).

3.2.2. Organização Internacional do Trabalho

Resolution n. 4 (International Labour Conference, Session 29th, 1948).

Estatuto do Tribunal Administrativo da Organização Internacional do Trabalho.

Regras de procedimento do Tribunal Administrativo da Organização Internacional do Trabalho.

3.2.3. Organização das Nações Unidas

International Law Commission, Fragmentation of international law: difficulties arising from the diversification and expansion of international law, Geneva, United Nations, 2006. 
International Law Commission, Projeto de Convenção da CDI sobre Imunidades Jurisdicionais do Estado e Seus Bens, ONU, 1975.

Office of Administration of Justice, A guide to resolving disputes, United Nations, New York, 2009.

Office of Administration of Justice, Seventh activity report, 1 January to 31 December 2013.

Office of Staff Legal Assistance, Guiding principles of conduct for Office of Staff Legal Assistance (OSLA): affiliated counsel in the United Nations. United Nations, New York, 2010.

2005 World Summit Outcome Document.

Declaração do Milênio.

Estatuto da Corte Internacional de Justiça.

Estatuto do Tribunal Administrativo da Organização das Nações Unidas.

Estatuto do Tribunal de Apelação das Nações Unidas.

Estatuto do Tribunal de Disputas das Nações Unidas.

Regras de procedimento do Tribunal Administrativo da Organização das Nações Unidas.

Regras de procedimento do Tribunal de Apelação das Nações Unidas.

Regras de procedimento do Tribunal de Disputas das Nações Unidas.

Staff regulations da Organização das Nações Unidas.

Staff rules da Organização das Nações Unidas.

A/61/205 (20 de julho de 2006).

A/63/253 (24 de dezembro de 2008).

A/67/98 (18 de junho de 2012).

A/69/126 (15 de julho de 2014).

A/RES/351 (IV) A (24 de novembro de 1949).

A/RES/351 (IV) A-B (9 de dezembro de 1949).

A/RES/50/54 (11 de dezembro de 1995).

A/RES/55/2 (18 de setembro de 2000).

A/RES/55/258 (14 de junho de 2001). 
A/RES/56/253 (24 de dezembro de 2001).

A/RES/59/283 (13 de abril de 2005).

A/RES/60/1 (24 de outubro de 2005).

A/RES/61/1 (20 de setembro de 2013).

A/RES/61/261 (4 de abril de 2007).

A/RES/62/228 (22 de dezembro de 2007).

A/RES/64/233 (16 de março de 2010).

A/RES/888 (IX) (17 de dezembro de 1954).

A/RES/957 (X) (8 de novembro de 1955).

ST/SGB/2002/13 (1 de novembro de 2002).

ST/SGB/2010/3 (7 de abril de 2010).

ST/SGB/2014/1 (1 de janeiro de 2014).

\section{DOCUMENTOS NACIONAIS}

Constituição Federal do Brasil (1988).

Lei $n$. 1.060/1950 (1950).

Lei $n$. 5.584/1970 (1970).

\section{REFERÊNCIAS VIRTUAIS}

<lnweb90.worldbank.org/crn/wbt/wbtwebsite.nsf/(attachmentweb)/D8E566109293CC338 52578B200744CEF/\$FILE/BODecisionNo.453.pdf>

<siteresources.worldbank.org/EXTARCHIVES/Resources/WB_Historical_Chronology_19 44_2005.pdf>

<ultimainstancia.uol.com.br/conteudo/colunas/63075/decisao+do+stf+organismos+interna cionais+e+imunidade+a+jurisdicao+trabalhista.shtml>

<untreaty.un.org/UNAT/Overview.htm>

<untreaty.un.org/UNAT/Rules.htm>

<untreaty.un.org/UNAT/Statute.htm>

<untreaty.un.org/UNAT/Statute.htm>

$\langle$ www.avalon.law.yale.edu>

<www.icj-cij.org/court/index.php?p1=1\&p2=1>

<www.icj-cij.org> 
<www.ilo.org/dyn/triblex/triblexmain.detail?p_judgment_no=2120> <www.ilo.org/dyn/triblex/triblexmain.detail?p_judgment_no=2639> $<w w w . i l o . o r g / d y n / t r i b l e x /$ triblexmain.detail?p_judgment_no=2662> $<w w w . i l o . o r g / d y n / t r i b l e x /$ triblexmain.detail?p_judgment_no=2722> $<w w w . i l o . o r g / d y n / t r i b l e x /$ triblexmain.detail?p_judgment_no=2760> <www.ilo.org/dyn/triblex/triblexmain.detail?p_judgment_no=2833> $<w w w . i l o . o r g / d y n / t r i b l e x /$ triblexmain.detail?p_judgment_no=2860> <www.ilo.org/dyn/triblex/triblexmain.detail?p_judgment_no=2913> $<w w w . i l o . o r g / d y n / t r i b l e x /$ triblexmain.detail?p_judgment_no=3020> <www.ilo.org/dyn/triblex/triblexmain.detail?p_judgment_no=3073> <www.ilo.org/dyn/triblex/triblexmain.detail?p_judgment_no=3099> <www.ilo.org/dyn/triblex/triblexmain.detail?p_judgment_no=3105> <www.ilo.org/dyn/triblex/triblexmain.detail?p_judgment_no=3141> <www.ilo.org/dyn/triblex/triblexmain.detail?p_judgment_no=3256> <www.ilo.org/dyn/triblex/triblexmain.detail?p_judgment_no=3264> <www.ilo.org/dyn/triblex/triblexmain.detail?p_judgment_no=3295> <www.ilo.org/dyn/triblex/triblexmain.detail?p_judgment_no=3295> <www.ilo.org/dyn/triblex/triblexmain.detail?p_judgment_no=3337> <www.ilo.org/global/about-the-ilo/history> <www.ilo.org/global/standards/introduction-to-internationallabourstandards/lang-en/index.htm>

<www.ilo.org/public/english/bureau/leg/resolutions> <www.ilo.org/public/english/ethics/standards.pdf> <www.ilo.org/public/english/tribunal/about/rules> <www.ilo.org/public/english/tribunal/about/statute.htm> <www.ilo.org/public/english/tribunal/about/statute> <www.ilo.org/public/english/tribunal/about/statute> 〈www.ilo.org/public/english/tribunal/download/articleccenglish.pdf > <www.ilo.org/public/english/tribunal/membership> <www.ilo.org/wcmsp5/groups/public/---ed_protect/---protrav/---travail/documents/publicat ion/wcms_travail_pub_1.pdf> <www.imf.org/external/about/histcoop.htm> <www.imf.org/external/imfat/pdf/j2013_2.pdf> <www.imf.org/external/imfat/statute.htm> 
<www.iso.org/iso/home/about.htm>

<www.iso.org/obp/ui/\#search>

<www.leagle.com/decision/19831327717F2d610_11226.xml/MENDARO\%20v.\%20WO

RLD\%20BANK>

<www.ombudsassociation.org >

<www.strategic-culture.org/news/2014/03/30/un-and-issue-ukraine-general-assembly-vs-

un-security-council.html>

<www.un.org/en/aboutun/index.shtml>

<www.un.org/en/aboutun/structure/index.shtml>

<www.un.org/en/aboutun/structure/pdfs/un-system-chart-color-sm.pdf>

<www.un.org/en/ecosoc/about/index.shtml>

$<$ www.un.org/en/ecosoc/about/strengtheningofecosoc.shtml>

<www.un.org/en/ga/about/background.shtml>

<www.un.org/en/members/index.shtml>

<www.un.org/en/members/intergovorg.shtml>

<www.un.org/en/members/nonmembers.shtml>

$<$ www.un.org/en/oaj/appeals/jurisdiction.shtml>

<www.un.org/en/oaj/appeals/timelimits.shtml>

<www.un.org/en/oaj/dispute/jurisdiction.shtml>

<www.un.org/en/oaj/dispute/pdf/court_etiquette.pdf>

<www.un.org/en/oaj/legalassist/about.shtml>

<www.un.org/en/oaj/legalassist/contact.shtml>

<www.un.org/en/oaj/legalassist/pdf/osla_consel_code_of_conduct.pdf>

$<$ www.un.org/en/oaj/unjs/efiling.shtml>

<www.un.org/en/oaj/unjs/office.shtml>

<www.un.org/en/oaj/unjs/pdf/guide_to_resolving_disputes_en.pdf>

<www.un.org/en/oaj/unjs/pdf/Seventh_activity_report_OAJ.pdf>

$<$ www.un.org/en/ombudsman/contact.shtml>

<www.un.org/en/ombudsman/help.shtml>

<www.un.org/en/ombudsman/index.shtml>

<www.un.org/en/ombudsman/issues.shtml>

<www.un.org/en/ombudsman/meddivision.shtml>

<www.un.org/en/ombudsman/medservices.shtml>

<www.un.org/en/ombudsman/principles.shtml> 
<www.un.org/en/ombudsman/what.shtml>

$<$ www.un.org/en/sc/about/>

<www.un.org/en/sc/about/functions.shtml>

$<$ www.un.org/sg/sg_role.shtml>

<www.worldbank.org/en/about/history> 